\title{
ESTUDO BIBLIOMÉTRICO DE TESES E DISSERTAÇÕES DE PROGRAMAS STRICTO SENSU EM ADMINISTRAÇÃO SOBRE RESPONSABILIDADE SOCIAL EMPRESARIAL
}

\author{
A BIBLIOMETRIC STUDY OF THESES FROM \\ BUSINESS ADMINISTRTION \\ DEGREESON CORPORATE SOCIAL RESPONSIBILITY
}

Recebido em: $30 / 10 / 2012$ Aprovado em: 18/01/2013
Avaliado pelo sistema double blind review
Editora Científica: Manolita Correia Lima

\begin{abstract}
MARIA TEREZA SARAIVA DE SOUZA mariaterezasaraivas@gmail.com
UNIVERSIDADE NOVE DE JULHO
\end{abstract}

\section{IARA REGINA DOS SANTOS PARISOTTO}

UNIVERSIDADE REGIONAL DE BLUMENAU

\section{CELSO MACHADO JUNIOR}

UNIVERSIDADE DE SÃO CAETANO DO SUL

\section{JOSÉ CARLOS BARBIERI}

ESCOLA DE ADMINISTRAÇÃO DE SÃO PAULO/FUNDAÇÃO GETÚLIO VARGAS

\begin{abstract}
RESUMO
O objetivo deste trabalho foi verificar as características das dissertações e teses que tratam do tema Responsabilidade Social Empresarial (RSE) em programas stricto sensu em administração no Brasil. A pesquisa exploratória e descritiva foi realizada por meio de análise documental e de conteúdo, com abordagem qualitativa e quantitativa. Tratou-se de um estudo longitudinal, com dados de I998 a 2009. Verificou-se uma evolução quantitativa em relação ao total de trabalhos defendidos na área, principalmente nos últimos cinco anos da análise. Houve predominância de estudos dos temas responsabilidade social, governança corporativa, ética, sustentabilidade empresarial e mercado de baixa renda. A região Sudeste destaca-se com a participação de $70,3 \%$ na área, seguida da região Sul. Entre as dez instituições que mais produzem, $80 \%$ encontram-se na região Sudeste. Vinte e oito IES particulares contribuíram com $60,2 \%$ de produção na área. A FGv/sp tem o maior volume de defesas na área de RSE.

Palavras-chave: teses e dissertações; programas stricto sensu em Administração; responsabilidade social empresarial.
\end{abstract}

\footnotetext{
ABSTRACT

The purpose if this study was to verify the characteristics of dissertations and theses that deal with the theme of Corporate Social Responsibility (CSR) in Brazilian Business Administration degrees. The exploratory and descriptive research was performed through document and content analysis, with a qualitative and quantitative approach. This was a longitudinal study, using data from 1998 to 2009. A quantitative evolution related to the total amount of studies in the area was seen, especially over the last five years of the analysis. There was a predominance of theses on social responsibility, corporate governance ethics, corporate sustainability and the low-income market. The Southeast region accounts for $70.3 \%$ of the studies, followed by the South region. Of the ten most productive institutions, eight are located in the southeast. Twenty-eight private HEIS were responsible for $60.2 \%$ of the region's production. The FGV/ SP HEI accounts for the largest volume of studies in the area of CSR.

Keywords: theses and dissertations; Business Administration graduate degrees; corporate social responsibility.
} 


\section{INTRODUÇÃO}

A Responsabilidade Social Empresarial (RSE) tem sido amplamente discutida nos últimos anos, tanto no âmbito das organizações quanto na academia, tendo em vista sua relevância institucional assumida pelas empresas quando se posicionaram como um dos atores sociais responsáveis pela melhoria do cenário socioeconômico (PEREIRA;CAMPOS FILHO, 2007).

Passador, Canopf e Passador (2005) afirmam que este tema, apesar de discutido por diversas áreas do conhecimento, ainda apresenta muita divergência. Para alguns, a Responsabilidade Social representa a obrigação legal; para outros, é vista como dever fiduciário. Alguns a traduzem como prática social, como papel social e como função social e há, ainda, os que a associam com o comportamento eticamente responsável.

RSE é um tema controverso a começar pela denominação. Muitos textos utilizam a expressão Responsabilidade Social Corporativa (RSC), do inglês Corporate Social Responsibility, na qual a palavra corporate refere-se às empresas constituídas na forma de sociedade anônima de capital aberto, segundo Barbieri e Cajazeira (2012). Para esses autores, os questionamentos sobre a responsabilidade social dessas empresas surgiram em decorrência da separação entre acionistas e dirigentes e dos problemas de agência, questões que lhes são exclusivas, de modo que essa expressão só valeria para esse tipo de empresa. Embora a expressão RSE se aplique a qualquer tipo de empresa, inclusive às de capital aberto, nesse trabalho também será utilizada RSC quando os autores citados a utilizarem.

Não é objetivo desse trabalho discorrer sobre os vários entendimentos sobre RSE e nem haveria espaço suficiente para isso.A sua importância no mundo empresarial cresceu com a polêmica em torno do texto de Milton Friedman, que entendia ser a responsabilidade social das empresas a maximimização de lucro aos acionistas dentro da lei; qualquer outra forma de responsabilidade seria uma proposta subversiva ao capitalismo (FRIEDMAN, 1982). A partir daí muito se escreveu sobre esse tema e muitas definições sobre RSE surgiram. Uma das mais influentes foi a de Carroll (1979, p. 500): "responsabilidade social das empresas compreende as 
expectativas econômicas, legais, éticas e discricionárias que a sociedade tem em relação às organizações em um dado período”. Até hoje se ouvem os ecos dessa definição na medida em que as questões legais, econômicas e éticas foram destacadas, retirando a importância da filantropia como era vista até então. Modernamente, um dos mais promissores entendimentos sobre responsabilidade social empresarial é vista como meio para alcançar o desenvolvimento sustentável (BARBIERI; CAJAzEIra, 20I2). Dentro desse contexto, a norma internacional ISO 26000 apresenta a seguinte definição:

Responsabilidade de uma organização pelos impactos de suas decisões e atividades na sociedade e no meio ambiente, por meio de um comportamento ético e transparente que: contribua para o desenvolvimento sustentável, inclusive a saúde e o bem-estar da sociedade; leve em consideração as expectativas das partes interessadas; esteja em conformidade com a legislação aplicável e seja consistente com as normas internacionais de comportamento; e esteja integrada em toda organização e seja praticada em suas relações (ABNT, 20IO).

Moretti e Campanário (2009, p. 70) comentam que "comparações entre as diversas abordagens sobre RSE poderão fornecer insighs para uma discussão mais fundamentada a respeito das direções que o debate tomou nesta última década e suas perspectivas futuras”. A sedimentação de um conceito definitivo tem se tornado um dos desafios mais presentes no debate acadêmico, tendo em vista que os conceitos, correntes teóricas e fatos históricos se sobrepõem de forma relacional, facultam aos pesquisadores um aspecto dicotômico quanto à estruturação de evolução do conceito (PEREIRA; CAMPOS FILHO, 2007).Grande parte da produção do conhecimento científico na área de administração é proveniente de teses e dissertações, fruto dos programas de pós-graduação stricto sensu. No entanto, não se sabe o que se produz sobre RSE nesses trabalhos Desta forma, a seguinte questão de pesquisa é proposta neste trabalho: quais as características das dissertações e teses que tratam do tema RSE em programas stricto sensu em administração no Brasil?

A área de Administração, Ciências Contábeis e Turismo possui I49 cursos stricto sensu. Desse total, os programas stricto sensu de administração 
correspondem a 56 mestrados acadêmicos, 32 doutorados e 38 mestrados profissionalizantes (CAPES, 20I2). Com o aumento desses programas, desde sua origem, aumentou também o número de teses e dissertações ao longo das últimas décadas. Em função desse aumento nas pesquisas, a área de Administração vem sendo objeto de estudo, principalmente sobre o que é produzido nos anais do Encontro da Associação Nacional de Pós-Graduação e Pesquisa em Administração (ENANPAD) e em periódicos nacionais.

Apesar do aumento nas pesquisas, ainda são poucos estudos que se atêm à produção de teses e dissertações dos programas de pós-graduação stricto sensu em administração no Brasil, principalmente na área de RSE. Desta forma,esta pesquisa visa a preencher essa lacuna.

Assim, o objetivo deste trabalho é verificar as características da produção científica das dissertações e teses que tratam do tema ser, em programas stricto sensu de administração, do Brasil, no período de 1998 a 2009.A estrutura do trabalho está organizada em mais quatro seções além desta seção introdutória. Na seção seguinte é apresentada a fundamentação teórica, que aborda a produção do conhecimento científico, as pesquisas sobre a produção científica na área de responsabilidade social em administração no Brasil. A terceira seção discorre sobre os procedimentos metodológicos adotados no estudo: coleta, análise e tratamento dos dados. A quarta seção apresenta os resultados da pesquisa, enquanto a quinta seção faz a análise e discussão desses resultados. Na última seção, nas considerações finais, são sintetizadas as principais conclusões, apresentadas as limitações da pesquisa e as recomendações para estudos futuros. 


\section{FUNDAMENTAÇÃO TEÓRICA}

A fundamentação teórica aborda a produção do conhecimento científico e as pesquisas sobre a produção científica na área de RSEem administração no Brasil.

\section{PRODUÇÃO DO CONHECIMENTO CIENTÍFICO}

A produção do conhecimento científico é resultado do trabalho de pesquisadores, que têm como uma das suas principais atividades a publicação dos resultados da pesquisa em periódicos e eventos, da linha estudada na comunidade científica a quepertencem, como meio de desenvolver o conhecimento.

Bertero, Caldas e Wood (2005) frisam que uma das características importantes do conhecimento científico é a possibilidade de acumulação, pois a produção do conhecimento ocorre no tempo. Não é obra de uma ou algumas pessoas, mas uma sequência de estudos que levam ao prosseguimento daquilo que outras pessoas iniciaram. Esses sistemas explicativos se inserem num processo ininterrupto de investigação, o que faz da ciência uma instituição social, dinâmica e cumulativa que amplia de forma permanente e contínua as fronteiras do conhecimento (TARGINO, 2000).

Para Leite Filho (2008), os programas de pós-graduação são os formadores de pesquisadores, professores, mestres e doutores que contribuem para produção do conhecimento. Assim, a vocação e as linhas de pesquisa dos programas provocam a renovação e a robustez da produção científica refletida na divulgação de seus trabalhos.

Momm (2009) entende que o conhecimento se torna científico quando a informação é registrada e divulgada, permitindo que outros indivíduos a utilizem e a transmitam por meio do compartilhamento entre os pares. Nesse sentido, a comunicação científica desempenha um papel de suma importância porque "[...]consiste na divulgação dos resultados das pesquisas à comunidade científica e a outros especialistas interessados, de forma a favorecer a geração e a disseminação de conhecimentos e de atividades de 
pesquisas"(CURTY; BOCCATO, 2005, p.IO6). Meis e Leta (1996) frisam que, devido à enorme produção científica disponível no mundo para os pesquisadores, passa a ser necessária uma superespecialização em áreas específicas do saber, sob pena de não se conseguir ler todas as informações pertinentes a um determinado tema.

Na visão de Targino (2000),é a comunicação científica que favorece ao produto (produção científica) e aos produtores (pesquisadores) a necessária visibilidade e possível credibilidade no meio social em que produto e produtores se inserem.

Há centros, indivíduos e grupos que são mais influentes do que outros. Uma das características do conhecimento científico é sua forma de distribuição não equitativa. Se fosse usada uma analogia, a distribuição do conhecimento e de capacitação científica estaria positivamente correlacionada à distribuição de renda e de riqueza: quem mais produz em conhecimento e tecnologia é quem mais avança no processo desenvolvimentista global (BERTERO; CALDAS; WOOD,2005;MEADOWS, I999;PRICE, I976).

Tal fato foi comprovado por Leite Filho (2008) ao analisar a publicação na área de Contabilidade. Nesta análise, foi possível verificara existência de concentração de autoria vinculada a poucas instituições, que apresentaram as mais altas freqüências relativas nos veículos de publicação estudados, denotando indícios de uma elite de pesquisadores e instituições detentoras dos maiores percentuais de publicação na área analisada. O mesmo ocorre com a produção da área de Recursos Humanos,que está concentrada em alguns programas: $50 \%$ dos trabalhos apresentados provêm de três instituições, localizadas nas regiõesSudeste e Sul, as mais desenvolvidas do país (TONELLI et al.,2003).

Uma publicação acadêmica é a expressão do estudo de um autor ou grupo de autores num momento particular. E, sendo assim, uma análise da literatura produzida pode permitir compreender um campo de estudo por meio de uma análise quantitativa de modo a identificar e analisar a base da produção científica de uma determinada área do conhecimento (LORDSLEEM et al.,2009). 


\section{PRODUÇÃO CIENTÍFICA EM RESPONSABILIDADE SOCIAL NA ÁREA DEADMINISTRAÇÃO NO BRASIL}

No Brasil, em razão do aumento no volume de produções científicas nas áreas de conhecimento ligadas à administração, verificam-se pesquisadores que buscam elaborar balanços críticos das publicações científicas em diferentes disciplinas, procurando avaliar a qualidade dos trabalhos que são produzidos (HOCAYDEN-DA-SILVA; ROSSONI;FERREIRA, 2008).

Passador, Canopf e Passador (2005) tiveram como principal objetivo analisar algumas abordagens de RSE propostas nos anais dos ENANPADS até 2004. Concluíram que, apesar de muitos títulos em comum nas bibliografias dos artigos apresentados, existem diferentes interpretações do tema responsabilidade social.Com base no resgate teórico realizado, os autores classificaram as abordagens referenciadas em: responsabilidade social como modismo, os liberais, neoliberais e afins, legitimação social, a questão ética e responsabilidade social corporativa.

Moretti e Figueiredo (2007) realizaram uma pesquisa bibliométrica nos anais do ENANPAD, no período de 2003 a 2006, na área temática de gestão social e ambiental, com um total de 208 artigos analisados. Destes, $43 \%$ se referiam ao tema sustentabilidade, $26 \%$ às ONGS, $21 \%$ àgestão e $10 \%$ eram relacionados aos fundamentos da área, foco de estudos dos autores. Em 2003, foram publicados 39 (19\%) artigos. Em 2004,o ano mais produtivo, 64 (31\%); em 2005, 5I(24\%) e em 2006, 54(26\%). Concluíram que no marco teórico do campo de estudos da RSE predomina a reprodução do discurso de alguns poucos autores e artigos nacionais e internacionais. A fragmentação do campo fica perdida pela não utilização das novas propostas em estudos posteriores.

Hocayden-da-Silva, Rossoni e Ferreira (2008) analisaram 549 artigos na área de administração pública e gestão social do ENANPAD, no período de 2000 a 2005. Os autores investigaram as seguintes categorias analíticas: número de autores por artigo, idioma do artigo, nacionalidade dos autores, instituição e estado de origem dos autores, tipo de pesquisa, método de pesquisa e estratégia de pesquisa. Do total de artigos analisados, I85 (34\%) 
são da área de gestão pública e governança, I68 (31\%) da área de políticas públicas, $4 \mathrm{I}(7 \%)$ da área de administração pública e 155 se referem àgestão social e ambiental, sendo 42 (27\%) em 2003, 63 (41\%) em 2004 e 50 (32\%) em 2005. Os autores frisaram que, como em outras áreas da administração, essa área também apresentou crescimento significativo, acompanhando o aumento da disciplina como um todo. Constataram que,em geral, a publicação científica na área de administração pública e gestão social é dominada por três instituições de ensino superior, que juntas foram responsáveis por $38,6 \%$ dos artigos publicados, sendo duas privadas - a FGV (SP) com $13,7 \%$ do total de artigos publicados e a FGV (RJ) com I3,5\% da publicação científica da área, e uma pública - UFBA (BA), que representa II, $5 \%$ dos artigos publicados. Ao analisar as dez instituições mais prolíficas da área, verificaram que, além das três já mencionadas, outras sete são responsáveis por $26,8 \%$ de produção na área, sendo elas: UFRGS (RS) e UNB (DF), cada uma com 5,I\% de participação; USP(SP), com 4,4\%; FJP (MG), com 3,6\%; UFMG (MG), COm 3,3\%; UFPE (PE), com 2,75 e UFSC (SC), com 2,6\%. Observaram uma concentração da produção na região Sudeste (42,6\% são do RJ e SP). Os estados de SP, RJ, MG, RS, PR e SC dominaram conjuntamente $83 \%$ do total de artigos científicos publicados. Tais resultados, segundo os autores, reforçam o argumento de que a produção nessa área é centralizada e estratificada.

Freire et al.(2008) analisaram a evolução da produção científica em responsabilidade social corporativa (RSC) nacional e internacional entre I950 e 2007. A base de investigação da pesquisa nacional foram I4 periódicos nacionais, classificados como qualis A e B e sete eventos; a base da produção internacional foram os artigos publicados na EBSCO, PROQUEST e SAGE. Foram definidas como palavras-chaves para a realização das buscas: ação social, cidadania corporativa, empresa cidadã, empresa socialmente responsável e responsabilidade social. Para fins de categorização, os autores utilizaram as proposições teóricas que relacionavam a RSC com outros temas, tais como cidadania corporativa, ética empresarial, gestão de stakeholders e sustentabilidade. Constataram que de 1960 a I97osurgiram I5 publicações;na década de 1990,Irartigos e nos anos de 2000, 282 artigos publicados na área, um salto quantitativo relevante. Dos 309 artigos publicados, 233 referiam-se 
ao tema RSC, I8 ao tema cidadania corporativa, 27 relacionavam-se àética empresarial, I3 àgestão de stakeholders e I8, àsustentabilidade. Verificaram que dos 233 artigos produzidos na área $\mathrm{RSC}, 3 \mathrm{I} \%$ estavam relacionados àética empresarial, 24\% àgestão de stakeholders, $20 \%$ àsustentabilidade; $\mathrm{I} 3 \%$,àcidadania corporativa e $\mathrm{I} 2 \%$ à própria RSC. Os autores concluíram que os estudos sobre responsabilidade social no Brasil ainda não atingiram o nível de complexidade das investigações realizadas no exterior, onde a pesquisa já está mais desenvolvida. Na literatura internacional são propostos modelos mais abrangentes, permanentemente criticados e reavaliados pelos próprios autores, o que não acontece no Brasil.

Moretti e Campanário (2009) caracterizaram o estado da arte da publicação brasileira, na área de RSE, por meio da análise do perfil detalhado dos autores, produção e das citações bibliográficas utilizadas no ENANPAD entre $1997 \mathrm{e}$ 2007.Foram analisados 216 artigos, distribuídos em quatro grupos temáticos, assim classificados: gestão social - atividades praticadas pelas empresas, relatos de casos práticos e gestão interna,marketing - ações de comunicação, balanço social e reação dos consumidores, fundamentos - razões da adoção das práticas de RSE, ética e cidadania e gestão ambiental - atividades das empresas e ambientes construído e natural, casos práticos das atividades das empresas. No grupo de gestão social foram apresentados 3I artigos no período analisado, sendo o primeiro artigo do ano 2000, enquanto 2006 foi o ano que teve maior número de artigos. No grupo de marketing foram apresentados 47 artigos, sendo que o ano 2007 foi o mais produtivo. $O$ grupo de fundamentos teve 80 artigos e o ano de maior representatividade foi 2007. No grupo de gestão ambiental, foram apresentados 58 artigos, sendo o ano de 2004 o mais produtivo.Em todas as áreas, mais de $60 \%$ da produção ocorreu no período de 2004 a 2007, destacando-se o grupo de gestão ambiental, com $77 \%$ de publicação nesse período, e o de fundamentos com 74\%. Dos autores, 5I,7\% são doutores e 25,4\%, mestres.Concluíram que a área de Responsabilidade Social Empresarial no Brasil tem pouca maturidade científica, com domínio de reprodução das mesmas ideias, assim como constataram Moretti e Figueiredo (2007). Verificaram que a produção dos anos anteriores foi pouco utilizada nos anos seguintes e 
houve repetição de livros, textos de administração e autores famosos pouco relacionados ao tema, observação originada na constatação de que poucas obras foram citadas muitas vezes, uma delas, 54 vezes (ASHLEY, 200I), outra, 52 vezes (ETHOS, 2002) e mais uma 49 vezes (MELO; FROES, I999), contribuindo pouco para o avanço científico da área, fato também constatado por Freire et al. (2008). 


\section{MÉTODO DE PESQUISA}

A fim de atender ao objetivo proposto, realizou-se uma pesquisa descritiva, com procedimento documental de abordagem qualitativa e quantitativa. Quantos aos objetivos, a pesquisa pode ser caracterizada como descritiva. Para Collis e Hussey (2005, p.22), "a pesquisa descritiva é aquela que descreve o comportamento dos fenômenos e é usada para identificar e obter informações, sobre as características de um determinado problema ou questão". Essa pesquisa caracteriza-se como pesquisa descritiva pela observação, classificação, análise e interpretação dos estudos de RSE nas referidas teses e dissertações.

Quantos aos procedimentos a serem utilizados, trata-se de uma pesquisa documental. Esse tipo de pesquisa se justifica quando se organizam informações que se encontram dispersas, dando a essas informações novo valor como fonte de consulta; tem, também utilidade para apontar tendências futuras. Consideram-se documentos relatórios de pesquisa, relatórios de empresa, tabelas estatísticas, documentos oficiais, entre outros (RAUPP; BEUREN, 2003). Nessa pesquisa foram utilizados relatórios e informações divulgadas pelo banco de dados da CAPES (CAPES, 20IOa, 20Iob, $2010 c$, 2010d), que foram armazenados e classificados de forma que fossem úteis para a pesquisa.

Com relação à abordagem do problema, a metodologia empregada foi qualitativa e quantitativa. $\mathrm{O}$ aspecto qualitativo da pesquisa deve-se ao uso da análise documental que Bardin (2009) define como um conjunto de operações, com vistas a classificar o conteúdo de um documento de uma forma diferente da original, facilitando, posteriormente, sua consulta, conseguindo o armazenamento de uma forma acessível e facilitada ao pesquisador. A análise de conteúdo foi utilizada para a definição de categorias de estudo, "as categorias são rubricas ou classes, as quais reúnem um grupo de elementos sob um título genérico, agrupamento esse efetuado em razão das características comuns destes elementos" (BARDIN, 2009, p.I45). $\mathrm{O}$ aspecto quantitativo deve-se ao uso da quantificação tanto na coleta 
quanto no tratamento dos dados por meio de técnicas estatísticas descritivas (RICHARDSON;PERES, 1989).

Os estudos longitudinais descrevem eventos ao longo do tempo e exigem que os dados sejam coletados das mesmas unidades de amostra, em diversos pontos no tempo.Esses dados representam uma série temporal de observações, permitindo mapear elementos e observar tendências (HAIR et al., 2005). Em termos de delineamento temporal, essa pesquisa trata-se de um estudo longitudinal, com dados de um período de I2 anos, 1998 a 2009, que corresponde a quatro triênios de avaliação dos programas de pósgraduação stricto sensu da CAPES. A opção por esse tipo de delineamento é justificada pela possibilidade de verificar as transformações ocorridas na área ao longo do tempo.

\section{DELIMITAÇÃO DO UNIVERSO}

Hair et al. (2005) mencionam que a população ou universo é a totalidade de todos os elementos que compartilham algum conjunto comum de características. A amostra investiga um pequeno subconjunto da população para daí tirarconclusões sobre suas características, podendo ser probabilística ou não probabilística. Entre as amostras não probabilísticas, encontra-se a amostragem por julgamento ou intencional, em que o julgamento do pesquisador é usado para selecionar elementos de amostra que o pesquisador acredita representarem a população alvo - grupo completo de elementos relevantes para um fim específico, com certas características do plano e das perguntas de pesquisa formuladas (HAIR et al., 2005; RICHARDSON; PERES, 1989). A população definida para este estudo foram os programas stricto sensu da grande área de Ciências Sociais Aplicadas, área de Administração. No portal da Coordenação de Aperfeiçoamento de Pessoal de Nível Superior (CAPES, 2orod), foram levantados, os cursos recomendados e reconhecidos, em junho de 20I0, perfazendo um total 335 programas divididos em 3I doutorados, 74 mestrados acadêmicos e 30 mestrados profissionais. Para o desenvolvimento desta pesquisa, a amostra foi do tipo intencional, da qual foram selecionados os programas stricto sensu em Administração, excluindo-se do estudo os programas das áreas de Ciências Contábeis e 
Turismo. Foram identificados Io9 programas de pós-graduação stricto sensu em Administração, sendo 27 doutorados, 55 mestrados acadêmicos e 27 mestrados profissionalizantes.

\section{PROCEDIMENTOS DE COLETA DE DADOS}

Rudio (2003) afirma que para cada tipo de informação que se deseja obter, existe uma variedade de instrumentos que podem ser utilizados e modos diferentes para operá-los. A coleta de dados iniciou-se em junho de 2010 (CAPES, 20IOa, 20Iob, 20IOc, 20Iod). O levantamento inicia-se em I998, que é o ano em que a CAPEs passou a disponibilizar os dados pelo portal, e se encerra em 2009, ano que antecede o período de levantamento dos dados do último triênio analisado, como mostra a Tabela I.

Tabela 1 Triênios Analisados

\begin{tabular}{|l|l|}
\hline Triênios Analisados & Periodo \\
\hline $1^{\circ}$ Triênio & 1998,1999 e 2000 \\
\hline $2^{\circ}$ Triênio & 2001,2002 e 2003 \\
\hline $3^{\circ}$ Triênio & 2004,2005 e 2006 \\
\hline $4^{\circ}$ Triênio & 2007,2008 e 2009 \\
\hline
\end{tabular}

O estudo levantou os dados das Instituições de Ensino Superior - IES que possuíam cursos recomendados e reconhecidos durante o período de levantamento de 1998 a 2009, e disponíveis no portal do CAPES no ano de 20Io. Foi constatado que dez IES perderam o credenciamento da CAPES nesse período, perfazendo um total de 303 dissertações em administração, que não estão contidas neste estudo.

A Coleta de dados teve início na ficha de avaliação dos programas (CAPES, 20IOC), de onde foram extraídos os seguintes dados: nome completo da IES, SIGLA da IES, dependência - pública ou privada, modalidade do curso - mestrado, doutorado ou mestrado acadêmico, ano de início das atividades dos programas. Do caderno corpo docente, vínculo e formação (CAPES, 20IOa), foram obtidos os dados sobre os docentes: nome completo dos docentes vinculados ao programa, tipo de vínculo com o programa - 
permanente ou colaborador, ano início de atividades na universidade, carga horária, ano de conclusão do doutorado, área de formação do doutorado, universidade em que se formou, caso sejainstituição brasileira ou país em que fez o doutorado. Dos cadernos de Teses e Dissertações (CAPES, 20Iob), as seguintes informações foram levantadas: nome do estudante, título obtido (mestrado profissional, acadêmico ou doutorado), ano de obtenção do título, título do trabalho, orientador, membros da banca e agência financiadora, se for o caso. No Banco de Teses do portal da CApes (20rra) foram pesquisados os resumos, palavras-chave e linha de pesquisa. Os dados coletados nos cadernos de indicadores foram agrupados e organizados em uma única planilha do software Excel-2007, com um total de 13.656 teses e dissertações, produzidas nos programas de pós-graduação stricto sensu, na área de Administração no Brasil, de 1998 a 2009.

\section{PROCEDIMENTOS DE ANÁLISE E CLASSIFICAÇÃO DOS DADOS}

Colauto e Beuren (2003, p.I4I) afirmam que "na fase de interpretação de dados no trabalho monográfico, o pesquisador busca analisar mais profundamente os dados que tabulou e organizou na etapa anterior". A identificação das teses e dissertações foi realizada com a utilização da análise de conteúdo, que obtém os dados por meio da observação sistemática do texto escrito, vendo a frequência com que as palavras e temas principais ocorrem e identificando o conteúdo e as características de informação presentes no texto. A análise de conteúdo trabalha com mensagens que são categorizadas, manipulando essas mensagens para evidenciar os indicadores, que permitam inferir sobre outra realidade que não a da mensagem. (HAIR et al., 2005; BARDIN, 2009). O procedimento de análise dos dados teve sua primeira etapa baseada na leitura e classificação dos 13656 títulos de teses e dissertações, buscando palavras-chave que tivessem relação com a dimensão social, de acordo com as definições de Barbieri e Cajazeira (2012); Carrol (1979); ABNT (20I0). Foram encontradas 643 teses e dissertações com essas características. Flick (2004) menciona que o objetivo da codificação aberta é expressar dados e fenômenos em forma de conceitos, desembaraçando os dados, classificando por unidades de significado (uma palavra, sequências curtas 
de palavras). Dessa forma, os temas foram classificados em i4 categorias. Essa categorização em palavras-chave está resumida no Quadro I.

Quadro 1 Categorias de Palavras

\begin{tabular}{|c|c|}
\hline Nome da Categoria & Palavras-chave \\
\hline Balanço social & Relatório social \\
\hline Conflitos socioambientais & Conflito ambiental; Conflito socioambiental \\
\hline Diversidade nas organizações & Diversidade nas organizações \\
\hline Ética & $\begin{array}{l}\text { Ethics, Ética empresarial, Ética nos negócios, Ética organizacional } \\
\text { e Conduta ética }\end{array}$ \\
\hline Governança corporativa & Governança e Governança solidária \\
\hline Inclusão digital & Exclusão digital \\
\hline Inclusão social nas organizações & $\begin{array}{l}\text { Inclusão social nas empresas, Profissional portador de deficiên- } \\
\text { cia e Pessoa com deficiência }\end{array}$ \\
\hline Marketing social & $\begin{array}{l}\text { Marketing relacionado à causa social e Comportamento socioam- } \\
\text { biental }\end{array}$ \\
\hline Mercado de baixa renda & Consumidor de baixa renda \\
\hline Mercado para terceira idade & Consumidor da terceira idade e Terceira idade \\
\hline Responsabilidade social & $\begin{array}{l}\text { Cidadania corporativa, Cidadania empresarial, Fair Trade, Gestão } \\
\text { socialmente responsável, Gestão socioambiental, Prática social, } \\
\text { Projeto social, Responsabilidade social corporativa, Responsa- } \\
\text { bilidade Social Empresarial, Responsabilidade socioambiental, } \\
\text { Responsividade, Socialmente, Socialmente responsável e Sus- } \\
\text { tentabilidade social }\end{array}$ \\
\hline Responsabilidade socioambiental & $\begin{array}{l}\text { Norma socioambiental; Gestão socioambiental; Incorporação de } \\
\text { questões ambientais e sociais; Responsabilidade (social/ ambien- } \\
\text { tal/socioambiental) }\end{array}$ \\
\hline Sustentabilidade empresarial & $\begin{array}{l}\text { Índice de sustentabilidade; Negócio sustentável; Organização } \\
\text { sustentável; Relatórios de sustentabilidade; Sustentabilidade } \\
\text { corporativa }\end{array}$ \\
\hline Voluntariado nas organizações & Voluntariado e Voluntário \\
\hline
\end{tabular}

A análise foi realizada em quatro etapas: a primeira análise originou as palavras-chave e as categorias; na segunda análise essas palavras-chave foram utilizadas como fonte de busca na planilha para encontrar trabalhos não identificados; na terceira análise foram realizadas consultas em resumo e palavras-chave dos títulos que se apresentavam dúbios ou com múltiplas possibilidades de agrupamentos; e na quarta análise, verificou-se a coerência dos agrupamentos das I4 categorias. As várias etapas de análise justificaram- 
se pela necessidade de aumentar a acurácia dos dados.

Procedimentos de tratamento dos dados

Os dados foram armazenados e tabulados em planilhas compatíveis com o software Microsoft Excel 2007 e sua descrição e análise foi realizada pela estatística descritiva, utilizando como principal recurso a distribuição de frequência e a média. A análise percentual também foi utilizada, pois possibilita a comparação e evita que os números absolutos gerem interpretações errôneas. 


\section{RESULTADOS DA PESQUISA}

O Gráficor compara a evolução do número de teses e dissertações em RSE com o total dos trabalhos defendidos entre 1998 e 2009, em programas stricto sensu em administração, bem como a percentagem que representam em relação ao total.

Gráfico 1 Evolução das Teses em Responsabilidade Social Empresarial de 1998 a 2009

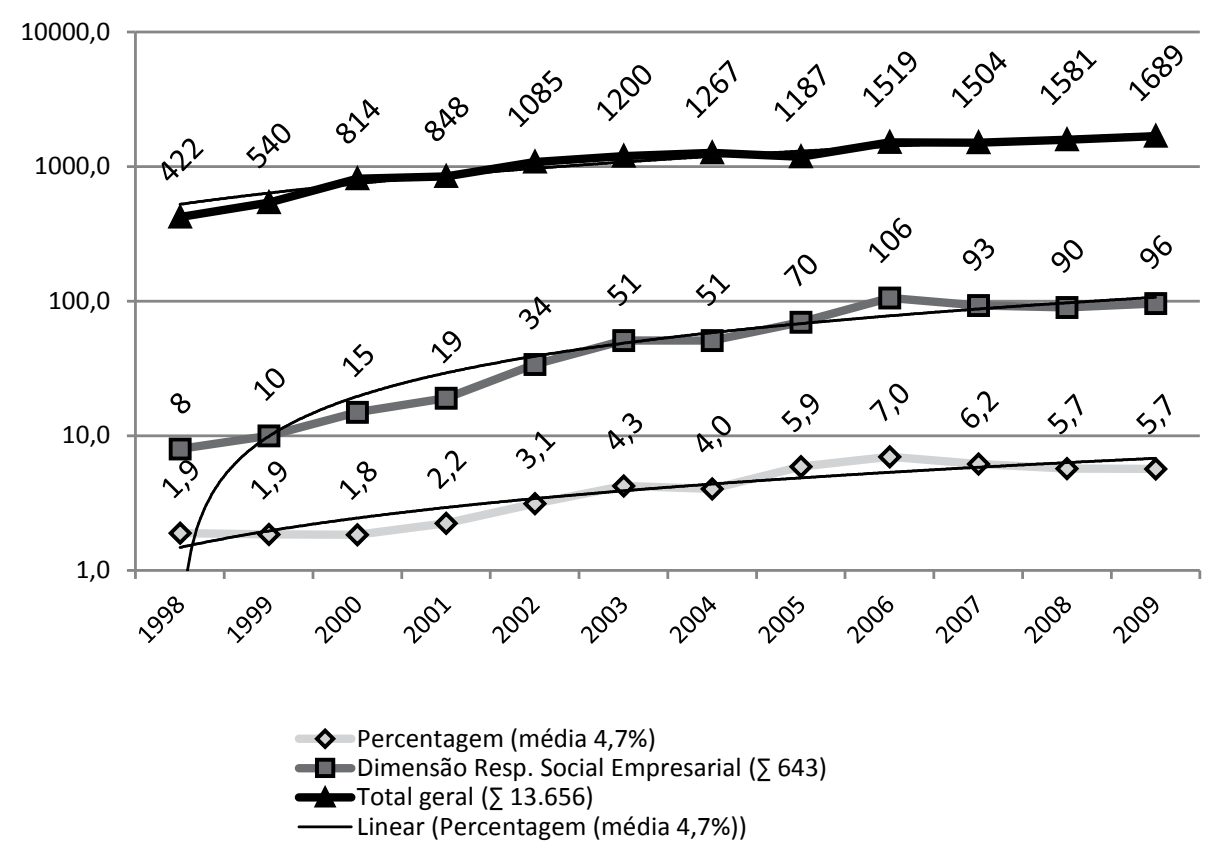

Nota: O eixo das ordenadas está formatado em escala logarítmica.

É possível observar a evolução quantitativa tanto do total de teses e dissertações, quanto dos trabalhos em RSE, defendidas no período de I998 a 2009, que mostrou uma evolução até o ano de 2006, com uma tendência de estabilidade a partir de então. O somatório dos trabalhos em 
RSE do período de estudo é de 643 , que representa $4,7 \%$ do total de 13.656 trabalhos apresentados. Esses dados confirmam a tendência de aumento da participação dos trabalhos em RSE, pois os últimos cinco anos de análise apresentam valores superiores ao da média geral. Como destaque positivo, o ano de 2006 apresentou uma participação de $7 \%$ desses trabalhos. O tema RSE foi subdividido em vários subtemas, que nortearam os agrupamentos de palavras-chave em I4 categorias, como mostra o Gráfico 2.

Gráfico 2 Distribuição dos Trabalhos em RSE de 1998 a 2009

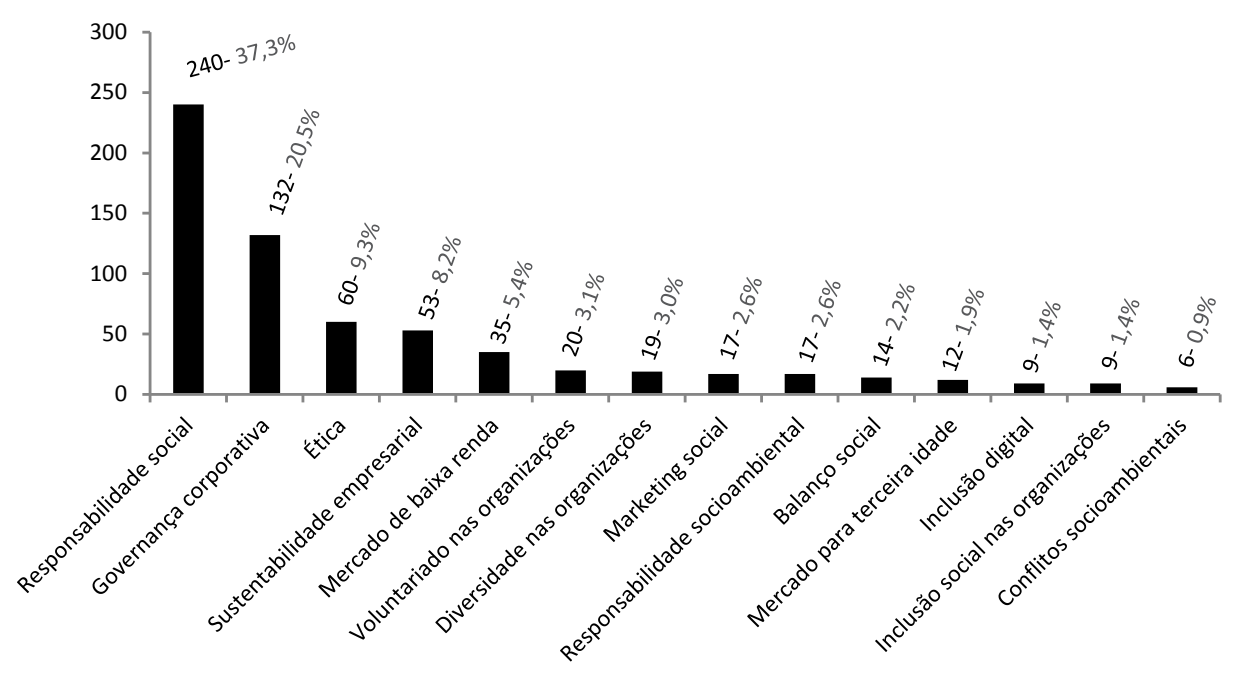

A Tabela 2 apresenta o desempenho dos temas em RSE ao longo do período de análise, complementando assim a informação do Gráfico 2. 
Tabela 2 Distribuição dos Trabalhos em rSE por Tema e Ano de 1998 a 2009

\begin{tabular}{|c|c|c|c|c|c|c|c|c|c|c|c|c|c|}
\hline \multirow[b]{2}{*}{ Temas RSE } & \multicolumn{13}{|c|}{ Anos de Análise } \\
\hline & 1998 & 1999 & 2000 & 2001 & 2002 & 2003 & 2004 & 2005 & 2006 & 2007 & 2008 & 2009 & Total \\
\hline Responsabilidade social & 1 & 1 & 5 & 11 & 13 & 26 & 18 & 30 & 42 & 27 & 33 & 33 & 240 \\
\hline Governança corporativa & & 1 & 1 & 2 & 5 & 11 & 14 & 18 & 23 & 17 & 16 & 24 & 132 \\
\hline Ética & 5 & 1 & 2 & 2 & 8 & 9 & 7 & 3 & 6 & 8 & 6 & 3 & 60 \\
\hline Sustentabilidade empresarial & & & 1 & 1 & & 1 & 1 & 4 & 10 & 13 & 9 & 13 & 53 \\
\hline Mercado de baixa renda & & & & & & & 2 & 1 & 6 & 6 & 9 & 11 & 35 \\
\hline $\begin{array}{l}\text { Voluntariado nas } \\
\text { organizações }\end{array}$ & & 1 & & & 4 & 1 & 5 & 1 & 2 & 2 & 3 & 1 & 20 \\
\hline Diversidade nas organizações & & & & 1 & 1 & & & 4 & 4 & 2 & 3 & 4 & 19 \\
\hline Marketing social & & & 1 & 1 & 1 & 1 & 2 & 3 & 2 & 4 & 2 & & 17 \\
\hline $\begin{array}{l}\text { Responsabilidade } \\
\text { socioambiental }\end{array}$ & & 1 & & & & & & & 4 & 3 & 5 & 4 & 17 \\
\hline Balanço social & & 3 & 2 & & 1 & 1 & & 2 & & 4 & 1 & & 14 \\
\hline Mercado para terceira idade & 1 & 2 & 1 & 1 & 1 & & 1 & & 2 & 2 & & 1 & 12 \\
\hline Inclusão digital & & & & & & & 1 & 4 & 2 & 1 & & 1 & 9 \\
\hline $\begin{array}{l}\text { Inclusão social nas } \\
\text { organizações }\end{array}$ & & & 1 & & & 1 & & & 2 & 2 & 3 & & 9 \\
\hline Conflitos socioambientais & 1 & & 1 & & & & & & 1 & 2 & & 1 & 6 \\
\hline Total geral & 8 & 10 & 15 & 19 & 34 & 51 & 51 & 70 & 106 & 93 & 90 & 96 & 643 \\
\hline
\end{tabular}

Foi verificada a predominância de teses e dissertações voltadas para os temas: responsabilidade social com 240 trabalhos (37,3\%) e governança corporativa com 132 trabalhos $(20,5 \%)$. Na sequência, aparecem os seguintes temas: ética com 60 trabalhos $(9,3 \%)$, sustentabilidade empresarial com 53 trabalhos $(8,2 \%)$, mercado de baixa renda com 35 trabalhos $(5,4 \%)$, voluntariado nas organizações com 20 trabalhos (3,1\%), diversidade nas organizações com 19 trabalhos (3\%), marketing social com i7 trabalhos $(2,6 \%)$, responsabilidade socioambiental com i7 trabalhos (2,6\%), balanço social com I4 trabalhos $(2,2 \%)$, mercado voltado àterceira idade com I2 trabalhos (I,9\%), inclusão digital com nove trabalhos ( $\mathrm{I}, 4 \%$ ), inclusão social nas organizações com nove trabalhos $(\mathrm{I}, 4 \%)$ e conflitos socioambientais com seis trabalhos $(0,9 \%)$.

Observa-se que o tema responsabilidade social apresentou tendência de crescimento até o ano de 2006, quando registrouseu ponto mais alto. 
Na sequência, os valores são estáveis. Já o temagovernança corporativa cresceu a partir do ano de 2002, com certa variabilidade,com alguns picos ocorrendo nos anos de 2006 e 2009. O tema ética empresarial registrou crescimento significativo a partir de 2002 , com relativa estabilidade. Observam-se ainda picos negativos (vales) de produção nos anos de $2005 \mathrm{e}$ 2009. A sustentabilidade empresarial apresentoupico de crescimento a partir de 2006, permanecendo com valores altos desde então. Vale destacar que o os relatórios de sustentabilidade passaram a ser publicados pelas empresas a partir de 2000, utilizando, predominantemente, a metodologia da gri. além disso, acriação do índice de sustentabilidade empresarial (ISE) Bovespa, em 2005, e a criação da norma internacional IsO 26000 , de responsabilidade social, podem ter contribuído para o acréscimo de trabalhos sobre sustentabilidade empresarial a partir de 2006. Para Barbieri e Cajazeira (2012, p.6I), tais fatos fazem parte de uma trajetória convergente entre os movimentos do desenvolvimento sustentável e o da RSE, formando o que vem sendo denominado de empresas sustentáveis.

O mercado de baixa renda apresentou tendência de crescimento a partir de 2006. Vale mencionar que as obras mais importantes que trouxeram essa temática foram publicadas por Prahalad (2005) e Hart (2005).Observase que temas, tais como diversidade nas organizações e responsabilidade socioambiental vêm apresentando maior volume de teses e dissertações, no intervalo dos últimos cinco anos, caracterizando-se como emergentes. Os demais itens apresentam variações aleatórias ao longo do tempo, com diferentes amplitudes.

A pós-graduação stricto sensu está dividida em três categorias: mestrado profissional, mestrado acadêmico e doutorado. O Gráfico3 mostra a distribuição das teses e dissertações nessas três categorias comparadas com o total de trabalhos defendidos no período analisado. 
Gráfico 3 Distribuição dos Trabalhos em RSE de 1998 a 2009

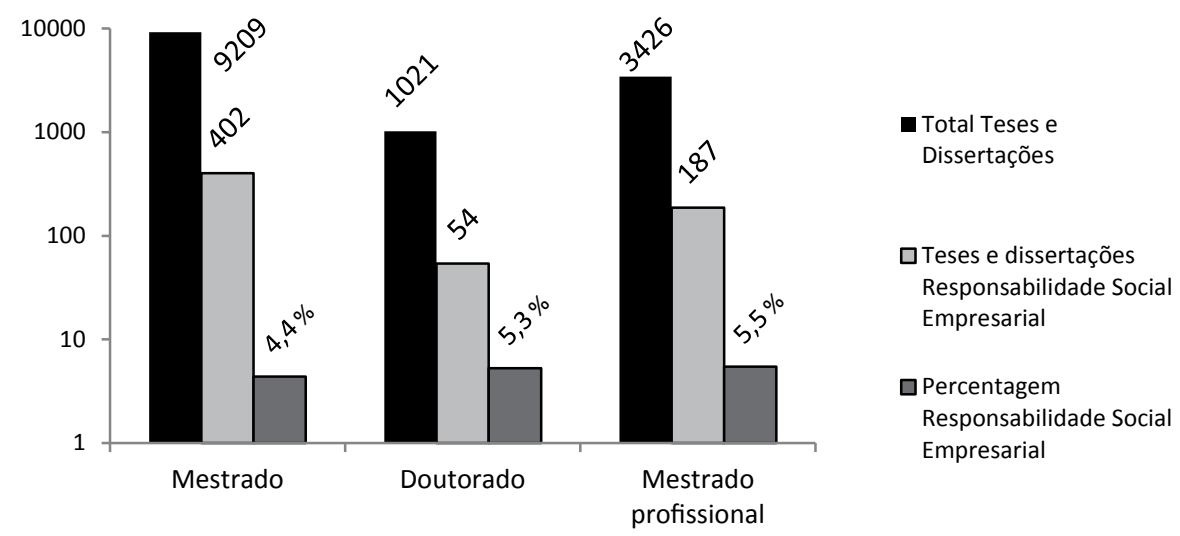

Nota: O eixo das ordenadas está formatado em escala logarítmica.

Verifica-se maior participação do mestrado acadêmico em termo absoluto, com 402 dissertações $(4,4 \%)$, enquanto que, em termo percentual, a predominância é do mestrado profissional, com i87 dissertações (5,5\%). Vale destacar que as pesquisas do mestrado acadêmico (402), com o menor percentual de participação de trabalhos em RSE, apresentam aproximadamente $70 \%$ a mais, em valores absolutos, que o somatório do doutorado e o mestrado profissional (24I).O Gráfico4 apresenta a distribuição das teses e dissertações por região geográfica do Brasil. 
Gráfico 4 Distribuição das Teses e Dissertações em RSE por Regiões do Brasil de 1998 a 2009

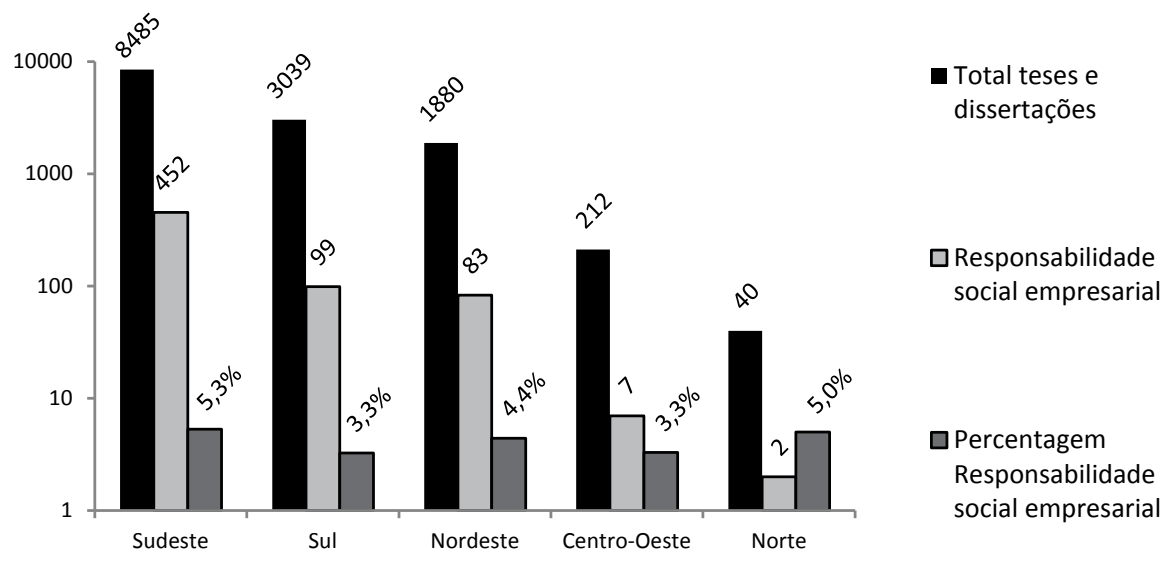

Nota: O eixo das ordenadas está formatado em escala logarítmica.

As regiões Sudeste (5,3\%), Norte (5\%), Nordeste $(4,4 \%)$, Sul $(3,3 \%)$ e Centro-Oeste $(3,3 \%)$ apresentam pouca discrepância, com um percentual relativamente próximo de teses e dissertações em RSE. Tal cenário mostra equilíbrio de interesse nas diversas regiões para a exploração desse tema.O Gráfico5 apresenta as dez IEs com maior volume de teses e dissertações em RSE de um total de 54 IES que apresentam trabalhos nesta área. 
Gráfico 5 Distribuição das teses e dissertações em RSE por IES de 1998 a 2009

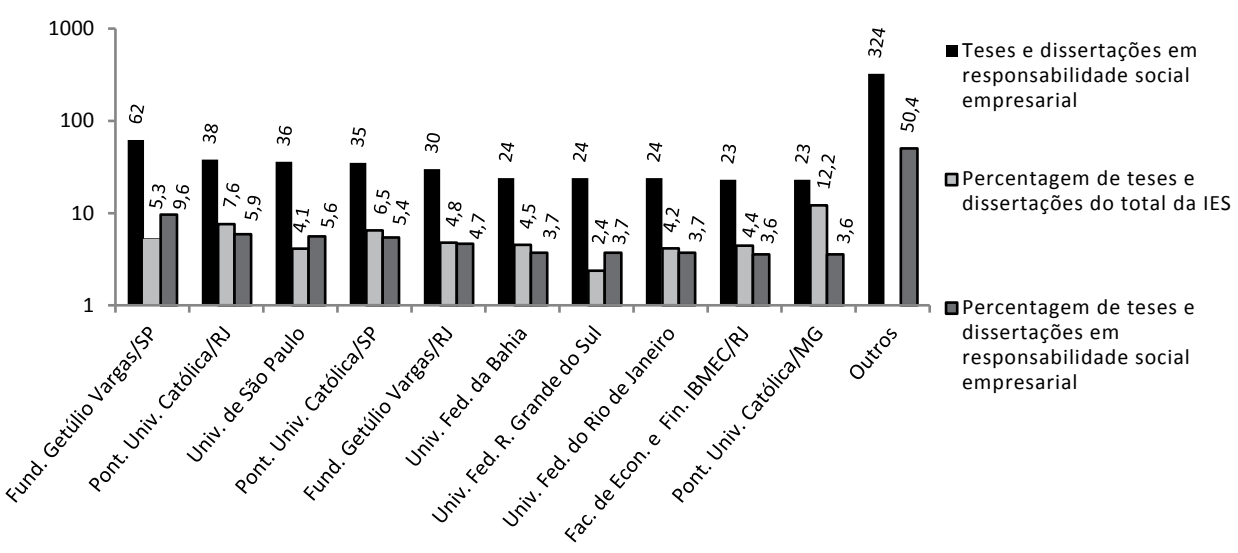

Nota: O eixo das ordenadas está formatado em escala logarítmica.

Esses dados apontam dois indicadores importantes para a análise: o primeiro quanto as teses e as dissertações da RSE representam em relação ao total produzido pela IES, enquanto o segundo apresenta o percentagem em relação ao total (643) de teses e dissertações em RSE.

Analisando, inicialmente, o desempenho das pesquisas em RSE dentro da própria IEs, a Pontifícia Universidade Católica de Minas Gerais (PUC/ MG) é a que possui maior participação interna de teses e dissertações em RSE com I2,2\%. Na sequência, aparece a Pontifícia Universidade Católica do Rio de Janeiro (PUC/RJ) com 7,6\%, a Pontifícia Universidade Católica de São Paulo (Puc/sp) com 6,5\% e a Fundação Getúlio Vargas, de São Paulo (FGV/SP), com 5,3\%. As demais IEs aparecem com uma participação interna de teses e dissertações inferior a 5\%. Além das dez IES mostradas no Gráfico 5 , há outras que, apesar de não serem as que mais produzem em,têm significativa participação (percentual superior a dez por cento) deste tema na sua produção de trabalhos no stricto sensu: Universidade Federal de Uberlândia (UFU) com I6,2\% (II trabalhos), Fundação Universidade 
de Pernambuco (FeSP/Upe) - I4,3\% (dois trabalhos), Universidade do Vale do Itajaí (Univali) - I3,I\% (II trabalhos), Fundação Instituto Capixaba de Pesquisa em Contabilidade Economia e Finanças (FUCAPE) - I2,5\% (dois trabalhos), Universidade Católica de Santos/sP (UCs/sP) - I2,I\% (I2 trabalhos), Universidade Federal do Ceará (UFC) - II,9\% (cinco trabalhos), Universidade Metodista de Piracicaba (UNIMEP) - II,I\% (I6 trabalhos) e Universidade Nove de Julho (Uninove) - Io,6\% (I3 trabalhos).

Ao analisar o desempenho de pesquisas da IES, em RSE, em relação ao total produzido no Brasil entre 1998 e 2009, verificou-se que a FGV/sp apresenta o maior volume de teses e dissertações em RSE (62), que representa 9,6\% do total produzido. A puc/RJ, por sua vez, se posiciona em segundo lugar, participando com $5,9 \%$ ( 38 trabalhos) $-38,5 \%$ a menos que a FGV/sP. $\mathrm{Na}$ sequência, as seguintes instituições também aparecem em destaque: Universidade de São Paulo (USP) - 5,6\%, PUC/sP (5,4\%), FGV/RJ (4,7\%), Universidade Federal da Bahia (UfBA) $-3,7 \%$, Universidade Federal do Rio Grande do Sul (UFRGS) - 3,7\%, Universidade Federal do Rio de Janeiro (UfRJ) $-3,7 \%$, Faculdade de Economia e Finanças IBmEC/RJ (3,6\%) e PUC/MG -3,6\%. As outras 44 instituições respondem por 50,4\% das teses e dissertações em RSE.

Das 63 IES analisadas entre 1998 e2009, foram identificadas 54 (85,7\%) com teses e dissertações emRSE, sendo que 26 IEs públicas contribuíram com 256 $(39,8 \%)$ das teses e dissertações no tema, enquanto que 28 IEs particulares contribuíram com 387 (60,2\%).O Gráfico 6 apresenta os treze (13) docentes da pós-graduação stricto sensu com maior número de orientandos que defenderam suas respectivas teses e dissertações na área de RSE, de um total de 369 . 
Gráfico 6 Distribuição participação dos docentes na orientação de teses e dissertações em RSE de 1998 a 2009

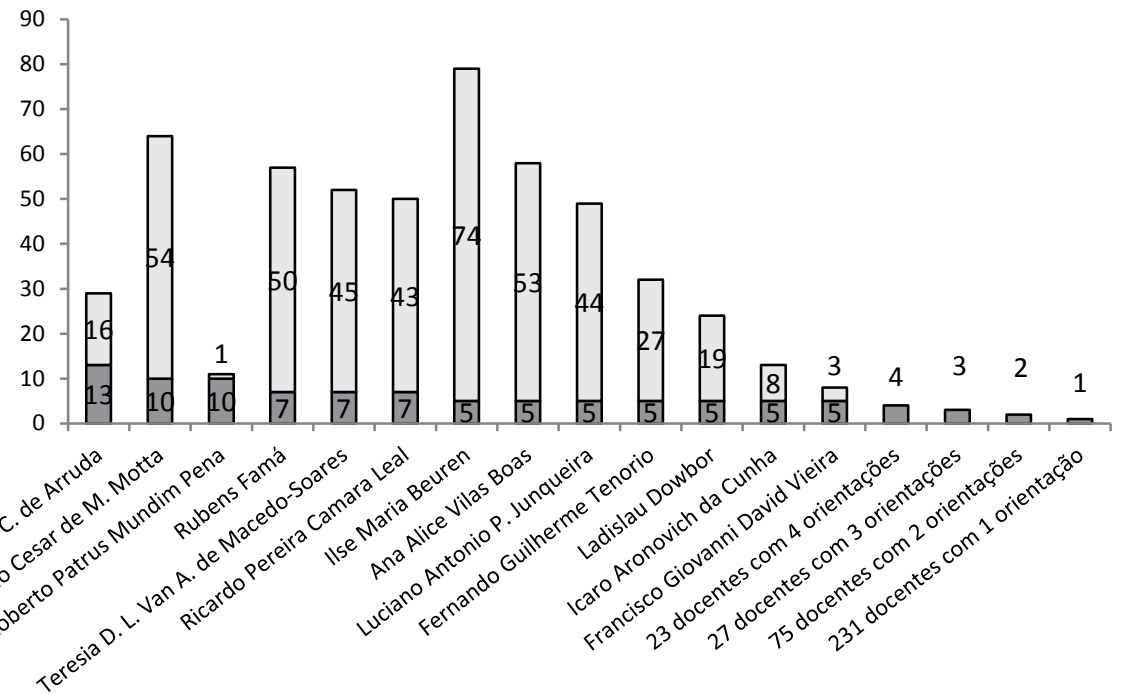

A professora Maria Cecília Coutinho de Arruda aparece com destaque portreze orientações de teses e dissertações em RSE pela EAESP/FGV. A docente realizou, no período de 1998 a 2009, 29 orientações; logo, 44,8\% de suas orientações trataram da RSE. Na sequência é mostrado o professor Paulo Cesar de Mendonça Motta, que participou, de 1998 a 2009, de 64 orientações, sendo dez (I5,6\%) na área de RSE. Todas as suas orientações ocorreram pela PUC/RJ. O docente Roberto Patrus Mundim Pena realizou no período de 1998 a 2009 onze (II) orientações, sendo que, destas dez, 90,9\% foram em RSE, na PUc/MG. Adicionalmente, os dados apontam que os docentes Rubens Famá, Teresia Diana L. Van A. de Macedo-Soares e Ricardo Pereira Camara Leal orientaram sete trabalhos em Rse. Os docentes Ilse Maria Beuren, Ana Alice Vilas Boas, Luciano Antonio Prates Junqueira, Fernando Guilherme Tenorio, Ladislau Dowbor, Icaro Aronovich da Cunha e Francisco Giovanni David Vieira orientaram cinco trabalhos em RSE, no período analisado. Os dados mostram que o percentual de teses e dissertações sobre RSE orientados por esses docentes é baixo comparado com o total de trabalhos orientados 
por eles.

Em destaque aparece a PUC/RJ, com dois docentes atuantes em RSE, os professores Paulo César de Mendonça Motta e Teresia Diana Lewe Van Aduard de Macedo-Soares, que somam I7 teses e dissertações de 38 orientadas em RSE, o que equivale a 44,7\% da produção desta IES, nesta área do conhecimento. As demais IES aparecem apenas com um professor entre os treze que mais orientaram trabalhos em RSE.

O Gráfico7 mostra o número de alunos que receberam bolsa de estudos em RSE $(26,1 \%)$. O incentivo por meio de bolsas de pesquisa foi

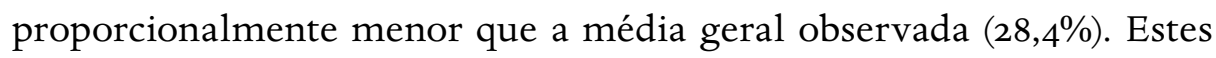
dados mostram que os discentes que pesquisam o tema RSE receberam aproximadamente $8 \%$ a menos de apoio àpesquisa que a média geral $(28,4 \%)$.

Gráfico 7 Distribuição das Bolsas de Pesquisa em RSE de 1998 a 2009

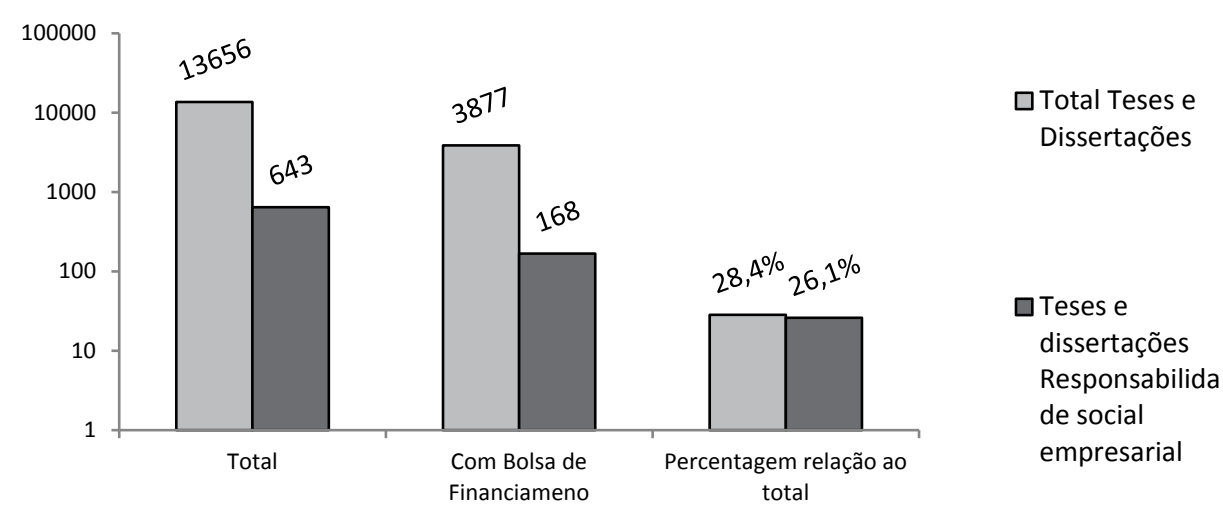

Nota: O eixo das ordenadas está formatado em escala logarítmica.

Na seção seguinte são apresentadas análises dos aspectos mais relevantes, bem como as discussões dos resultados obtidos à luz do referencial teórico. 


\section{ANÁLISE E DISCUSSÃO DOS RESULTADOS}

As teses e dissertações desenvolvidas no Brasil estão disponíveis no portal da CAPES (CAPES, 20Ira), desde I998. Assim, é possível afirmar que esses trabalhos se configuram como componentes de divulgação do conhecimento científico,conformeproposto por Momm (2009). Essas teses e dissertações sãoconsultadas e citadas em artigos apresentados em congressos científicos e periódicos, o que Targino (2000) e Curty e Boccato (2005) confirmam.

Os dados mostraram a evolução quantitativa superior em relação tanto ao total de teses e dissertações defendidas no período de 1998 a 2009 quanto dos trabalhos em RSE, corroborando os achados de Freire et al.(2008), Hocaydenda-Silva, Rossoni e Ferreira (2008), bem como as afirmações de Targino (2000) e Bertero, Caldas e Wood (2005) de que o conhecimento científico é obra de muitas pessoas, feitas por uma sequência de estudos que levam ao prosseguimento daquilo que outras iniciaram, criando um processo ininterrupto de investigação, que amplia de forma permanente as fronteiras do conhecimento.

Houve um aumento significativo de participação dos trabalhos em RSE nos últimos cinco anos (2005 a 2009), período este que representou 70,8\% da produção total, quando, comparado à produção de apenas 29,2\% entre 1998 e 2004. Os últimos cinco anos, portanto, apontam um aumento aproximado de $240 \%$ de produção em relação ao período anterior. Esses resultados confirmam as verificações de Moretti e Campanário (2009), que mostraram que mais de $60 \%$ de publicação da área ocorreu após o ano de 2003. Tais dados também reforçam as conclusões de Leite Filho (2008) quando afirma que os programas de pós-graduação, por meio de sua vocação e linhas de pesquisa, contribuem com a renovação e robustez da produção científica do país.

Das teses e dissertações produzidas, predominam as categorias responsabilidade social com $37,3 \%$ e governança corporativa com 20,5\%. Destacam-se, ainda as categorias: ética, com 9,3\% dos trabalhos, sustentabilidade empresarial, com $8,2 \%$, e mercado de baixa renda, com 5,4\%. Juntas, essas cinco categorias representam $8 \mathrm{I} \%$ da produção 
total, e as nove categorias restantes - voluntariado e diversidade nas organizações, marketing social, responsabilidade socioambiental, balanço social, mercado para a terceira idade, inclusão digital, inclusão social nas organizações, conflitos socioambientaiscompõemapenası $\%$ da produção.A predominância dos temas responsabilidade social, cidadania corporativa e ética também é constatada por Freire et al. (2008) e Moretti e Campanário (2009). No entanto, Moretti e Figueiredo (2007), contrapondo-se, observam maior destaque para o tema sustentabilidade ( $43 \%$ da publicação), enquanto as questões da responsabilidade social só representaram io\% das publicações. Possivelmente, essa diferença se deveao tipo de classificação utilizada pelos autores. Este conjunto de informações estabelece um perfil que possibilita maior compreensão dos trabalhos desenvolvidos nos Programas de PósGraduação Stricto Sensu em Administração, na área de ser, no Brasil, fato que vai ao encontro das conclusões de Lordsleem et al.(2009).

Existe maior participação, em termos absolutos, de dissertações provenientes do mestrado acadêmico, com 402 trabalhos $(4,4 \%)$. As dissertações de mestrado profissional aparecem na sequência, com I87 trabalhos (5,5\%), que, por sua vez, também se constituemna maior participação percentual, enquanto as teses do doutorado colaboram com 54 trabalhos (5,3\%). Moretti e Campanário (2009) observaram que,das publicações analisadas, 5I,7\% (2I2 autores) eram doutores e 25,4\% (I04 autores) eram mestres, número que se contrapõe ao resultado dessa pesquisa, em que as maiores participaçõessão dos mestrados, tanto em termos absolutos quanto percentuais. Esse fato indica que, apesar de os mestrados produzirem muitas pesquisas, boa parte delas nãosão publicadas.

Os programas de pós-graduação stricto sensu caracterizam-se por formar pesquisadores que obtêm seus respectivos títulos em administração, mestres ou doutores, mas que, naturalmente, irão se especializar em uma das vastas áreas desse campo do conhecimento. Dessa forma, os pesquisadores que optaram pela RSE em programas stricto sensu, em administração, têm maior potencial de se especializarem nessa área e desenvolverem suas futuras pesquisas no assunto tratado em suas respectivas dissertações ou teses, o que corrobora as conclusões de Meis e Leta (1996). 
Ao comparar quanto cada região produz de teses e dissertações em RSE, com relação ao total da área de administração, há pouca discrepância entre as IEs; mas, ao analisar o total de estudos na área de RSE, verificou-se que $70,3 \%$ das teses e dissertações desenvolvidas nessa área são da região Sudeste, I5,4\% da região Sul, I3\% são produzidas no Nordeste, I\% no Centro-Oeste e $0,3 \%$ na região Norte. Estes números são consonantes com a produção nacional de teses e dissertações em administração, em que as regiões Sudeste e Sul, juntas, produzem $84 \%$ do total. Em termos globais de produção de teses e dissertações na área de administração, de acordo com a afirmação de Bertero, Caldas e Wood (2005), Meadows (I999) ePrice (1976), a distribuição do conhecimento e de capacitação científica em administração está aparentemente correlacionada com a distribuição de renda e de riqueza, produzindo mais em conhecimento as regiões Sul e Sudeste. Tais resultados vão também ao encontro das conclusões de Hocayden-da-Silva, Rossoni eFerreira (2008), que identificaram as regiões Sul e Sudeste como responsáveis, conjuntamente, por $83 \%$ do total de artigos publicados na área.

Entre as dez universidades que mais produzem teses e dissertações em RSE, $80 \%$ encontram-se na região Sudeste, apenas uma pertence à região Sul e outra à região Nordeste. Outras 44 instituições respondem por $54,6 \%$ de teses e dissertações em RSE restantes. Vinte e oito IEs particulares contribuíram com $60,2 \%$ de produção na área de RSE, enquanto 26 IES públicas participaram com 39,8\% de produção na área. Destacam-se nesta área FGV/sP, PUC/RJ, USP e PUc/sP o que corrobora as conclusões de Bertero, Caldas e Wood (2005), Leite Filho (2008), Meadows (1999), Price (1976) e Tonelli et al. (2003), que mostraramem seus estudos a concentração de autoria vinculada a poucas instituições de ensino.

Observa-se que as PUC/RJ, PUC/sP e PUC/MG configuram entre as dez IEs que desenvolvem estudos em RSE, que, de forma conjunta, representam I4,9\% do que foi produzido, fator este que pode estar relacionado à própria missão da PUC, cuja preocupação está voltada para a formação ética e solidária, bem como ao desenvolvimento humano e social. De forma análoga, a FGV/sP e FGV/RJ representam de forma conjunta I4,3\%. Este cenário mostra interesse 
dos pesquisadores destas IES no estudo em RSE. Hocayden-da-Silva, Rossoni e Ferreira (2008) não verificaram uma expressividade tão relevante para as Pontifícias Universidades Católicas; no entanto, também observaram que a FGV (SP e RJ) tem uma produção relevante em relação ao total da publicação na área.

A análise dos docentes que atuam em RSE mostra a concentração de pesquisadores nesta área do conhecimento. A PUC/RJ, responsável por 5,9\% do total das teses e dissertações em RSE, concentra $44,7 \%$ das defesas em dois pesquisadores - Paulo César de Mendonça Motta e Teresia Diana Lewe Van Aduard de Macedo-Soares, que somam I7 teses e dissertações de 38 da área. A FGv/sp, que possui maior volume de trabalhos defendidos em RSE, conta também com a docente mais produtiva na área, a professora Maria Cecília Coutinho de Arruda, que representa 21\% da produção da área nesta instituição. Os demais dez docentes que aparecem no Gráfico 6,também são nomes que se destacam na orientação de trabalhos em RSE. Estes dados apresentam aderência às conclusões de Bertero, Caldas e Wood (2005), Leite Filho (2008), Meadows (1999), Price (1976) e Tonelli et al. (2003), que observaram a concentração de autoria vinculada tanto a poucas instituições de ensino quanto ao número reduzido de pesquisadores. Nos estudos bibliométricos desenvolvidos por Moretti e Campanário (2009), Freire et al. (2008) e Moretti e Figueiredo (2007) não são citados nas obras analisadas por esses autores os artigos de docentes que mais orientam na área, o que parece indicar, como eles mesmos concluíram, um domínio da reprodução das mesmas ideias e a produção pouco utilizada de anos anteriores.

Com relação à distribuição de bolsas de pesquisa, observou-se que os pesquisadores da área de RSE receberam aproximadamente oito por cento menos de apoio à pesquisa que a média geral $(28,4 \%)$. 


\section{CONSIDERAÇÕES FINAIS}

O objetivo deste trabalho foi verificar as características da produção científica das dissertações e teses que tratam do tema Responsabilidade Social Empresarial, em programas Stricto Sensu, em administração do Brasil, no período de 1998 a 2009.

A análise das dissertações e tesesmostrou uma evolução quantitativa em relação ao total de trabalhos defendidos na área de RSE, principalmente nos últimos cinco anos da análise, com um aumento aproximado de $240 \%$ de produção em relação ao período anterior, destacando-se o ano de 2006.

Os dados mostram a predominância de teses e dissertações sobre os temasresponsabilidade social, governança corporativa, ética, sustentabilidade empresarial e mercado de baixa renda, que correspondem a $8 \mathrm{r} \%$ dos trabalhos da área, enquanto os nove temas restantes representamapenas $19 \%$.

O curso de mestrado profissional estabelece maior prevalência de trabalhos em RSE, com 5,5\% do total de trabalhos, enquanto o doutorado possui 5,3\% e o mestrado acadêmico participa com 4,4\%.

As regiões geográficas do Brasil também apresentaram discrepância na participação dos trabalhos, sendo que a região Sudeste se destaca na área de Responsabilidade Social Empresarial, seguida da região Sul. Entre as dez universidades que mais produzem teses e dissertações em RSE, $80 \%$ encontram-se na região Sudeste, apenas uma pertence à região Sul e outra à região Nordeste. Vinte e oito IEs particulares contribuíram com $60,2 \% \mathrm{de}$ produção na área de RSE, enquanto 26 IES públicas participaram com 39,8\% de produção na área. Destacam-se nesta área: PUC/MG, PUC/RJ e PUC/sP e $\mathrm{FGV} / \mathrm{SP}$ e FGV/RJ.

Entre os docentes que atuam em RSE, verificou-se concentração de pesquisadores nesta área do conhecimento. Destaca-se a PUC/RJ, responsável por $5,9 \%$ do total das teses e dissertações em RSE, que concentrou $44,7 \%$ das defesas em dois pesquisadores. A FGV/sp possui maior volume de trabalhos defendidos em RSE, concentrados em uma única docente, que orienta os trabalhos da área nesta instituição. 
O financiamento de pesquisa por meio de bolsas de estudo aos pesquisadores da área de Responsabilidade Social Empresarial foi 8\% menor que a média geral.

As dissertações e teses são importantes componentes na disseminação do conhecimento científico produzido no stricto sensu, pois os temas desses trabalhos retratam as linhas e os projetos de pesquisa do orientador. Assim, esta pesquisa, ao retratar o resultado dessas orientações na área de RSE, pode subsidiar futuros pesquisadores deste campo de estudo.

Uma das principais limitações desta pesquisa foi não considerar 303 dissertações de dez IES que foram descredenciadas pela CAPES, uma vez que esses trabalhos podem ter estudos desenvolvidos na área de RSE.

Recomenda-se, para futuras pesquisas, identificar os principais congressos e os periódicos científicos em que são divulgados os resultados das pesquisas das dissertações e teses em Responsabilidade Social Empresarial, de pós-graduação stricto sensu, em administração, assim como estudos que identifiquem as obras mais citadas e as abordagens teóricas e metodológicas desses trabalhos. 


\section{REFERÊNCIAS}

ASSOCIAÇÃO BRASILEIRA DE NORMAS TÉCNICAS (ABNT). NBR ISO 26000:2010. Diretrizes sobre responsabilidade social. Rio de Janeiro: ABNT, 2010.

ASHLEY, P. A. Ética e responsabilidade social nos negócios. São Paulo: Saraiva, 2001.

BARBIERI, J.C.; CAJAZEIRA, J.E.R. Responsabilidade social empresarial e empresa sustentável: da teoria à prática, 2.ed. São Paulo: Saraiva, 2012.

BARDIN, L. Análise de conteúdo.5 ed.Lisboa: Edições 70, 2009.

BERTERO, C. O.; CALDAS, M. P.; WOOD JR., T. Produção científica em administração no Brasil: o estado-da-arte. São Paulo: Atlas, 2005.

BEUREN, I. M.; LONGARAY, A. A. Como elaborar trabalhos monográficos em contabilidade:teoria e prática. São Paulo: Atlas, 2003.

CARROLL, A. B. A three-dimensional conceptual model of corporate performance. Academy of Management Review, v. 4, n. 4, 1979.

COLAUTO, R.; BEUREN, I. M. Coleta, Análise e Interpretação dos dados. In: BEUREN, I. M. (Org.). Como elaborar trabalhos monográficos em contabilidade: teoria e prática. São Paulo: Atlas, 2003. p.117-143.

COLLIS, J.; HUSSEY, R. Pesquisa em administração: um guia prático para alunos de graduação e pós-graduação. 2.ed. Porto Alegre: Bookman, 2005.

COORDENAÇÃO DE APERFEIÇOAMENTO DE PESSOAL DE NÍVEL SUPERIOR (CAPES). Relação de Cursos Recomendados e Reconhecidos. Disponível em: <http://www. capes.gov.br/cursos-recomendados>. Acesso em: 09/04/2012.

. Banco de Teses. Disponível em- <http://www.capes.gov.br/serviços/banco-deteses+>. Acesso em: 07/02/2011a.

. Caderno de Indicadores Corpo Docente, Vínculo, Formação. Disponível em: <http:// conteudoweb.capes.gov.br/conteudoweb/VisualizadorServlet?nome=_Doc_Out. pdf\&aplicacao=projetoRelacaoCurso +>. Acesso em: 14/07/2010a.

.Caderno de Indicadores Teses e Dissertações. Disponível em: <http:// conteudoweb.capes.gov.br/conteudoweb/VisualizadorServlet?nome=_Teses. pdf\&aplicacao $=$ projetoRelacaoCurso $+>$. Acesso em: 14/07/2010b.

. Fichas de Avaliação. Disponível em: <http://conteudoweb.capes.gov.br/ conteudoweb/AvaliacaoTrienalServlet?codigoPrograma+>. Acesso em: 14/07/2010c.

Relação de Cursos Recomendados e Reconhecidos. Disponível em: <http://www. capes.gov.br/cursos-recomendados>. Acesso em: 24/06/2010d.

CURTY, M. G.; BOCCATO, V. R. C. O artigo científico como forma de comunicação do conhecimento na área de ciência da informação. Revista Perspectivas em Ciência da Informação, Belo Horizonte, v. 10, n. 1, p. 94-107, 2005.

FLICK, U. Uma introdução a pesquisa qualitativa. 2.ed. Porto Alegre: Bookman, 2004. 
FREIRE, R.; SANTOS, S. R. O. S.; SOUZA, M. J. B. de; ROSSETTO, C. R.

Responsabilidade social corporativa: evolução da produção científica. In: CONGRESSO NACIONAL DE EXCELÊNCIA EM GESTÃO - CNEG, 4, 2008, Niterói. Anais..., Niterói: UFF, 2008.

FRIEDMAN, M. Capitalismo e liberdade. São Paulo: Abril Cultural, 1982.

HART, S. Capitalism at the Crossroads: The Unlimited Business Opportunities in Solving the World's Most Difficult Problems. Pennsylvania, Wharton School Publishing, 2005.

HAIR, J.F.; BABIN, B.; MOONEY, A.H.; SAMUEL, P. Fundamentos de Métodos de Pesquisa em Administração. Porto Alegre: Bookman, 2005.

HOCAYEN-DA-SILVA, A. J.; ROSSONI, L.; FERREIRA JR., I. Administração pública e gestão social: a produção científica brasileira entre 2000 e 2005. Revista de Administração Pública, Rio de Janeiro, v. 42, n. 4, p. 655-680, 2008.

Instituto Ethos de Empresas e Responsabilidade Social (ETHOS). Guia de Elaboração do Balanço Social 2002. Disponível em: <http://www.balancosocial.org.br/cgi/cgilua.exe/ sys/start.htm $>$. Acesso em: 23/04/2011.

LEITE FILHO, G. A. Padrões de produtividade de autores em periódicos e congressos na área de contabilidade no Brasil: um estudo bibliométrico.Revista de Administração Contemporânea, Curitiba, v. 12, n. 2, p. 533-554, 2008.

LORDSLEEM, N.L.C.; ARAÚJO, R.M.de; OLIVEIRA, B.M.K. de; ALEXANDRE, M. L. de O. Ensino e pesquisa em administração: um estudo bibliométrico de publicações do ENANPAD (2001-2008). Revista Ciências Administrativas, Fortaleza, v. 15, n. 2, p. 356-378,2009.

MEADOWS, A. J. A comunicação científica. Brasília: Briquet de Lemos, 1999.

MEIS, L.; LETA, J. O perfil da ciência brasileira. Rio de Janeiro: UFRJ, 1996.

MELO NETO, F. P.; FROES, C. Responsabilidade social \& cidadania empresarial: a administração do terceiro setor. Rio de Janeiro: Qualitymark, 1999.

MOMM, C. F. O Conhecimento Científico em Turismo no Brasil: Cursos de Pós-Graduação (Stricto Sensu) - período de 2000 a 2006. 131f. Dissertação (Mestrado em Ciências da Informação). Universidade Federal de Santa Catarina, Florianópolis, 2009.

MORETTI, S. L. do A.; CAMPANARIO, M. A. A produção intelectual brasileira em responsabilidade social empresarial - RSE sob a ótica da bibliometria,Revista de Administração Contemporânea, Curitiba, v. 13, edição especial, p. 68-86, 2009.

MORETTI, S. L. do A.; FIGUEIREDO, J. Análise Bibliométrica da produção sobre responsabilidade social das empresas no EnANPAD: evidências de um discurso monológico, Revista de Gestão Social e Ambiental, São Paulo, v. 1, n. 3, p. 21-38, 2007.

PASSADOR, C. S.; CANOPF, L.; PASSADOR, L. J. Apontamentos sobre a responsabilidade social no EnANPAD: a construção de um conceito. In: ENCONTRO ANUAL DA ANPAD - ENANPAD, 29., 2005, Brasília. Anais...Rio de Janeiro: ANPAD, 2005. 
PEREIRA, W. A.; CAMPOS FILHO, L.A. N. Investigação sobre as semelhanças entre os modelos conceituais da responsabilidade social corporativa, Revista de Gestão Social e Ambiental,São Paulo, v. 1, n. 1, p. 3-18, 2007.

PRAHALAD, C. K. A riqueza na base da pirâmide: como erradicar a pobreza com lucro. Porto Alegre, Bookman, 2005.

PRICE, D. J. S. O desenvolvimento da ciência: análise histórica, filosófica, sociológica e econômica. Rio de Janeiro: Livros Técnicos e Científicos, 1976.

RAUPP, F. M.; BEUREN, I. M. Metodologia da Pesquisa Aplicável às Ciências Sociais. In: BEUREN, I. M. (Org.). Como elaborar trabalhos monográficos em contabilidade: teoria e prática. São Paulo: Atlas, 2003, p.76-97.

RICHARDSON, R. J.; PERES, J. A. S. Pesquisa social: métodos e técnicas. 2. ed. São Paulo: Atlas, 1989.

RUDIO, F. V. Introdução ao Projeto de Pesquisa Científica. 31.ed. São Paulo: Vozes, 2003.

TARGINO, M. G. Comunicação científica: uma revisão de seus elementos básicos. Revista Informação \& Sociedade: Estudos, Paraíba, v. 10, n. 2, p.1-27, 2000.

TONELLI, M. J.; P. CALDAS, M.; LACOMBE, B. M.B.; TINOCO, T. Produção acadêmica em recursos humanos no Brasil: 1991-2000. Revista de Administração de Empresas, São Paulo, v. 43, n. 1, p. 1-18, 2003. 


\section{DADOS DOS AUTORES}

MARIA TEREZA SARAIVA DE SOUZA^ mariaterezasaraivas@gmail.com Doutora em Administração de Empresas pela EAESP/FGV

Instituição de vinculação: Universidade Nove de Julho

São Paulo/SP - Brasil

Áreas de interesse em pesquisa: Gestão Ambiental e Sustentabilidade

* Alameda Ministro Rocha Azevedo, 644, ap. 43 Jardim Paulista

São Paulo/SP or4Io-00o

\section{IARA REGINA DOS SANTOS PARISOTTO iaraparisotto@hotmail.com}

Doutora em Administração pela Uninove

Bolsista do Edital 05/2008 - PROPEX FURB

Instituição de vinculação: Universidade Regional de Blumenau

Blumenau/SC - Brasil

Áreas de interesse em pesquisa: Gestão Ambiental e Sustentabilidade, Ensino e

Pesquisa em Administração.

CELSO MACHADO JUNIOR celsomachado1@gmail.com

Doutor em Administração pela Uninove

Instituição de vinculação: Universidade de São Caetano do Sul

São Caetano do Sul/SP - Brasil

Áreas de interesse em pesquisa: Gestão ambiental e educação ambiental.

JOSÉ CARLOS BARBIERI jose.barbieri@fgv.br

Doutor em Administração de empresas pela EAESP/FGV

Instituição de vinculação: Escola de Administração de São Paulo/Fundação Getúlio Vargas

São Paulo/SP - Brasil

Áreas de interesse em pesquisa: Gestão ambiental e educação ambiental.

Essa pesquisa recebeu financiamento da cApes - Edital Proadministração. 